\title{
Capsiate treatment in liver surgeries may compromise its recovery ${ }^{1}$
}

Pedro Paulo Barros', Gisele Mara Silva Gonçalves', Gustavo Henrique da Silva', Maria Clara Villaça Dias Bastos", Loren Nogaroto Ramos", Marilia Marinello Fernandes"

'PhD, Full Professor, Researcher, Faculty of Pharmaceutical Sciences, Pontifícia Universidade Católica de Campinas (PUCCampinas), Brazil. Conception of the study, interpretation of data, manuscript writing, critical revision.

"Pharmacist, Faculty of Pharmaceutical Sciences, FAPIC (Fundo de Apoio à Iniciação Científica), PUC-Campinas, Brazil. Design of the study.

\section{Abstract}

Purpose: To investigate the effects of capsiate treatment on hepatic hyperplasia in partially hepatectomized rats.

Methods: The animals were divided into a Capsiate group (CPH), a Capsiate Post-Partial Hepatectomy group (CPPH) and a Partial Hepatectomy Control group (PH). CPH and CPPH animals received $60 \mathrm{mg} / \mathrm{kg} /$ day Capsiate for 30 days. Next, the rats underwent partial hepatectomy. CPPH animals continued to receive treatment for $48 \mathrm{~h}$ after partial hepatectomy. Liver tissue and intracardiac blood samples were obtained 24 or $48 \mathrm{~h}$ after $\mathrm{PH}$.

Results: Capsiate treatment interfered with hepatic parameters, reducing the number of mitoses and apoptosis and increasing blood ALT and alkaline phosphatase concentrations.

Conclusion: Capsiate treatment preceding hepatic surgery may compromise the initial period of postoperative recovery.

Key words: Alanine Transaminase. Aspartate Aminotransferases. Apoptosis. Mitotic Index. Rats. 


\section{Introduction}

Peppers are universally known for their pungency which is due to the presence of substances such as capsaicin, a capsaisinoid. There is a less spicy red pepper variety, $\mathrm{CH}-19$ (Capsicum annuum L.), a sweet pepper that contains capsinoids instead of capsacinoids. Capsinoids are analogous to capsaicin but are not spicy and contain three major compounds: capsiate (4-hydroxy-3methoxybenzyl (E)-8-methyl-6-nonenoate), dihydrocapsiate (4-hydroxy-3-methoxybenzyl 8-methylnonanoate), and nordihydrocapsiate ( 4 - h y d r ox y - 3 - m e t h ox y b e n z y I 7-methyloctanoate), respectively ${ }^{1-4}$.

Capsinoids were first studied at the end of the 1990's in Japan ${ }^{3,5}$ and specific studies of capsiate were later conducted in 2001 by Ohnuki et al. ${ }^{6}$.

Like capsacinoids, capsinoids and capsiate in particular have various therapeutic activities. Several studies have investigated the anticancer action of capsinoids and capsiate and dihydrocapsiate have been found to be able to prevent tumorigenesis in athymic mice, indicating the action of capsinoids on cancer prevention?.

Lee et $a l .{ }^{8}$ demonstrated that capsiate has highly protective effects against the inflammatory response and angiogenesis produced in the skin by ultraviolet $B$ radiation by inhibiting the production of reactive oxygen species and the activity of c-Src kinase. In addition to inhibiting pathological angiogenesis, capsiate can reduce the vascular 'permeability caused by vascular endothelial growth factor ${ }^{9}$.

Haramizu et al. ${ }^{10}$ reported that capsiate administered to rats in parallel to the execution of exercise reduced weight gain, being useful for the maintenance of an ideal weight. Kwon et al. $^{11}$ observed that capsiate improves glucose metabolism in a more efficient manner than capsaicin in rats. Using an experimental rat model, Li et al. ${ }^{12}$ observed that capsiate can produce beneficial effects on ethanol-induced gastric mucosa injury.

In Brazil, capsiate has been extensively used for weight loss since it is expected to act on the acceleration of metabolism and on the reduction of body fat ${ }^{13}$.

In view of the antioxidant and antiinflammatory properties attributed to capsiate, we hypothesize that this substance may have a hepatoprotective action like other substances with the same properties such as quercetin ${ }^{14}$.

Thus, the aim of the present study was to investigate the effects of capsiate pretreatment on liver hyperplasia in partially hepatectomized rats.

\section{Methods}

The experimental protocols for this study were approved by the Animal Research Ethics Committee - Pontifícia Universidade Católica de Campinas (Protocol number: 018/2015), according to the Guide for the Care and Use of Laboratory Animals.

Forty-day-old male Wistar rats with a body weight of 250-260g were obtained from the Animal Facility of the Life Sciences Center (PUC-Campinas, Brazil). Throughout the experiments, the animals were maintained in rooms with controlled temperature $\left(23 \pm 1^{\circ} \mathrm{C}\right)$ under a 12-hour light/dark cycle. The animals were provided with pellet chow and water ad libitum.

Reagents were acquired from the following sources: capsiate (Pharmanostra ${ }^{\mathrm{TM}}$ ), vincristine sulfate (Libbs Farmaceutica ${ }^{\mathrm{TM}}$ ), and enzyme assay kit (LaborLab ${ }^{\mathrm{TM}}$ ). All other reagents were analytical grade.

\section{Partial hepatectomy}

Animals were divided into the following groups: Capsiate group (CPH), a Capsiate PostPartial Hepatectomy group ( $\mathrm{CPPH}$ ) and a Partial 
Hepatectomy Control group (PH), (Figure 1). $\mathrm{CPH}$ and $\mathrm{PH}$ animals were further divided into two subgroups each ( $\mathrm{CPH} 24, \mathrm{CPH} 48, \mathrm{PH} 24$ and $\mathrm{PH} 48 ; n=5$ in each subgroup). $\mathrm{CPH}$ and $\mathrm{CPPH}$ animals received $60 \mathrm{mg} / \mathrm{kg} /$ day capsiate dissolved in water for a volume of $1 \mathrm{~mL}$ and administered via a gastric tube for 30 days. The $\mathrm{PH}$ control group received $1 \mathrm{~mL}$ saline solution administered via a gastric tube for 30 days.

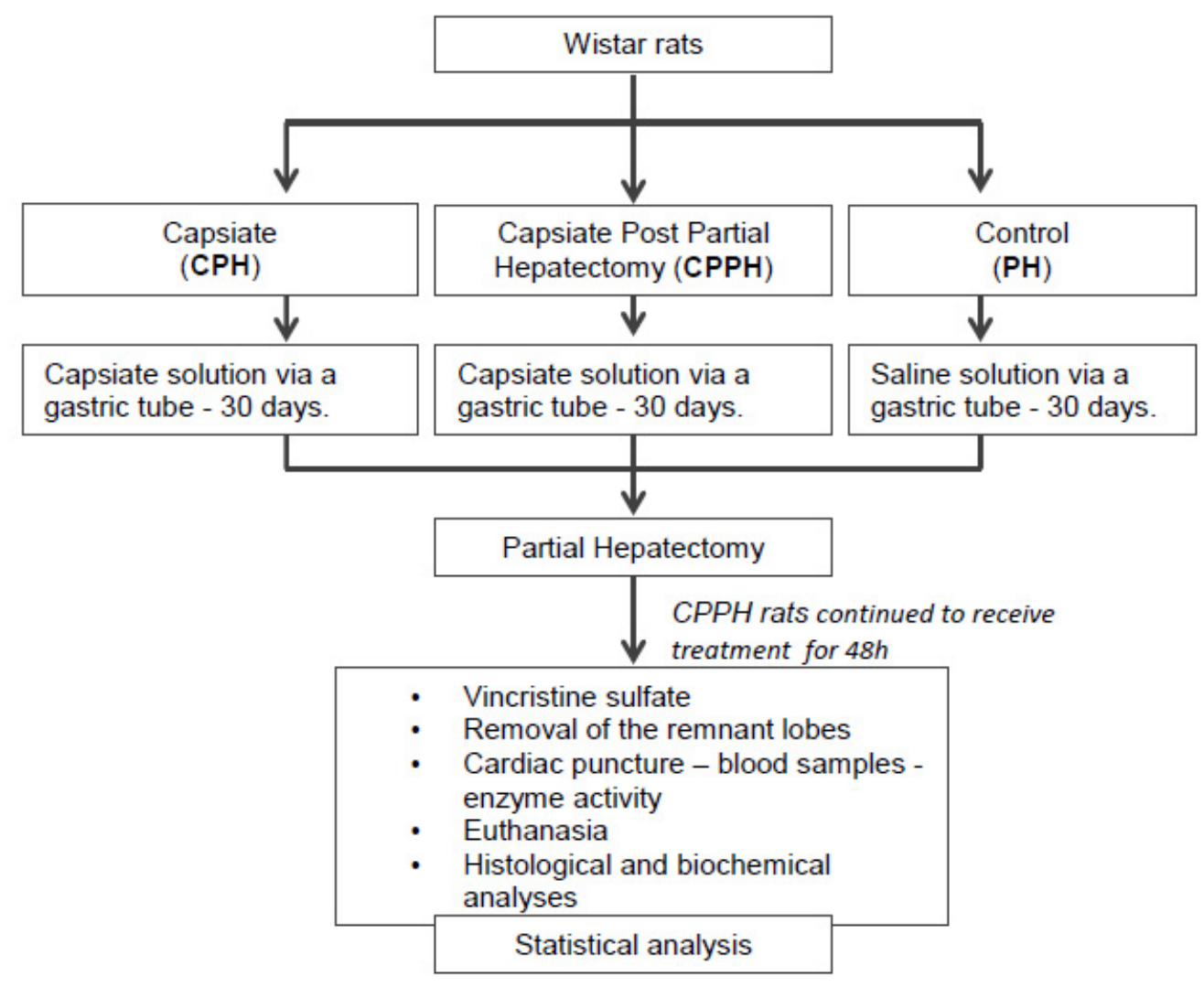

Figure 1 - Experimental design.

\section{Surgical procedure}

All surgical procedures were performed under anesthesia with $10 \mathrm{mg} / \mathrm{lg}$ xylazine and 70 $\mathrm{mg} / \mathrm{kg}$ ketamine, injected intraperitoneal. The rats underwent partial hepatectomy (about $70 \%$ removal of hepatic tissue) according to the method of Higgins and Anderson ${ }^{15}$. $\mathrm{CPPH}$ animals continued to receive treatment for $48 \mathrm{~h}$ after $\mathrm{PH}$. After 24 or $48 \mathrm{~h}$, according to the group to which they belonged, animals received an intraperitoneal injection of vincristine sulfate $(1 \mathrm{mg} / \mathrm{kg})$ in order to block the cell cycle of all hepatocytes at the $M$ phase. After $2 \mathrm{~h}$, the animals were anesthetized for removal of liver tissue. Three $\mathrm{ml}$ intracardiac blood samples were drawn for biochemical analysis, followed by euthanasia with ketamine and xylazine.

Histological processing

Liver tissue fragments were cut into $7 \mu \mathrm{m}$-thick slices and stained with 
hematoxylin-eosin (HE) and by the Feulgen method (FM). The FM allows to clearly visualize the hepatocyte nucleus and to identify the mitosis. Images were captured digitally using a photomicroscope (Nikon Eclipse E200 ${ }^{\mathrm{TM}}$ ) coupled to a camera (Nikon Colpix $4500^{\mathrm{TM}}$ ). Mitosis and apoptosis were quantified by microscopic analysis.

\section{Determination of enzyme activity}

The enzymatic activity of ALT, AST and alkaline phosphatase was determined in blood serum using commercial kit for Human samples (LaborLab ${ }^{\mathrm{m} \text { ) }}$ and a UV-Vis Varian ${ }^{\mathrm{m}}$ spectrophotometer.

\section{Data analysis}

Data are reported as number of findings in the microscopic analysis. Mitotic and apoptotic figures were counted in 20 fields per liver tissue section stained with $\mathrm{HE}$ and FM. Morphometry, AST, ALT and alkaline phosphatase data were analyzed statistically using Graph Pad PRISM software. The MannWhitney test $(p<0.05)$ was used for group comparisons.

\section{- Results}

The analysis of mitosis and number of apoptosis events showed a statistically significant reduction of the number of mitoses in the $\mathrm{CPH} 24$ group compared to the remaining groups and a significant reduction of the number of apoptosis in the $\mathrm{CPH} 48$ and CPPH48 groups (Figures 2 and 4). No significant variations were detected in the remaining groups. Enzyme activity differed significantly among group, as shown in Figure 3.

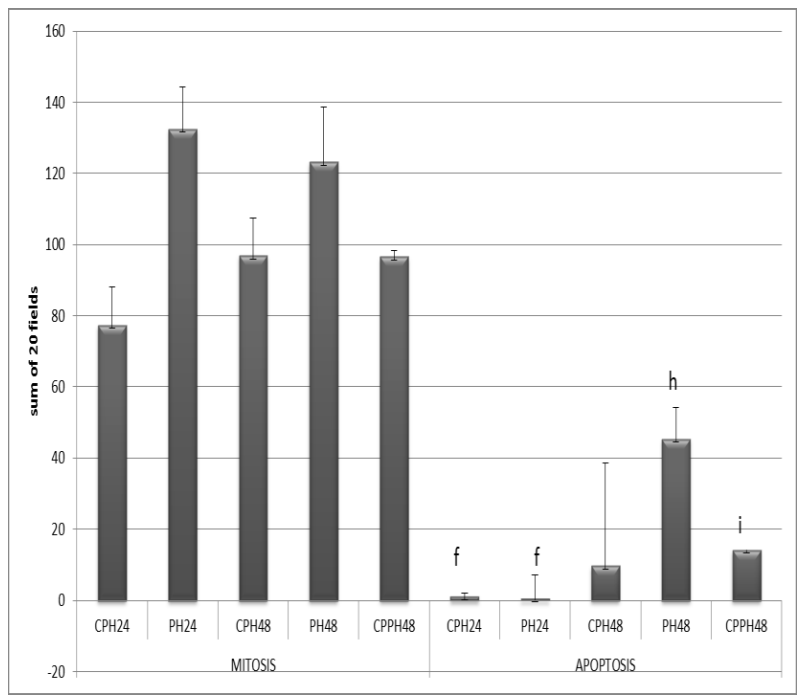

Figure 2-Mitosis and apoptosis. PH24, PH48: Groups examined 24 and $48 \mathrm{~h}$ after partial hepatectomy, respectively; $\mathrm{CPH} 24, \mathrm{CPH} 48$ : Capsiate-treated groups examined 24 and $48 \mathrm{~h}$ after partial hepatectomy, respectively. CPPH48: Group treated with capsiate before and after partial hepatectomy and examined $48 \mathrm{~h}$ after partial hepatectomy. The Mann-Whitney test showed a significant difference (values followed by different letters) when this group was compared to its respective control.

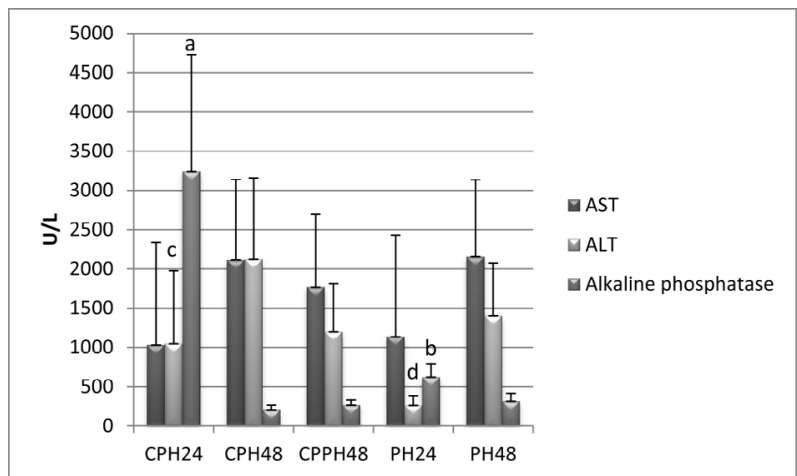

Figure 3 - Clinical parameters of rats submitted to Partial Hepatectomy, and Capsiate + Partial Hepatectomy. AST=Aspartate aminotransferase; ALT=Alanine aminotransferase. PH24, PH48: Groups examined 24 and $48 \mathrm{~h}$ after partial hepatectomy, respectively; $\mathrm{CPH} 24$, $\mathrm{CPH} 48$ : Capsiate-treated groups examined 24 and $48 \mathrm{~h}$ after partial hepatectomy, respectively. CPPH48: Group treated with capsiate before and after partial hepatectomy and examined $48 \mathrm{~h}$ after partial hepatectomy. The Mann-Whitney test showed a significant difference (values followed by different letters) when this group was compared to its respective control 


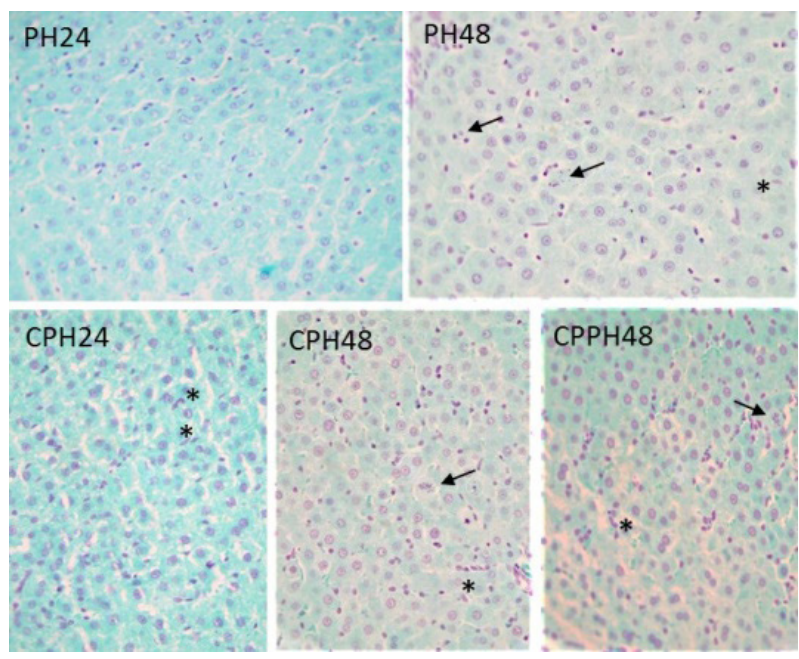

Figure 4 - Liver, Hepatocyte - Mitosis (asterisks) and apoptosis (arrows) in Wistar rats. Control groups examined 24 and $48 \mathrm{~h}$ after partial hepatectomy ( $\mathrm{PH} 24$ and $\mathrm{PH} 48$, respectively). $\mathrm{CPH} 24, \mathrm{CPH} 48$ : Capsiate-treated groups examined 24 and $48 \mathrm{~h}$ after partial hepatectomy, respectively. CPPH48: Group treated with capsiate before and after partial hepatectomy and examined $48 \mathrm{~h}$ after partial hepatectomy. (Feulgen stain, $x 400$ ).

\section{- Discussion}

Histological analysis from HE staining showed that no histological changes were detected in the liver of the studied groups, indicating absence of hepatic lesion due to the treatments / procedures performed.

The reduction in the number of mitoses observed in the group examined 24 and $48 \mathrm{~h}$ after treatment (Figures 2 and 4) suggests that there was a deceleration of the mitotic process and that this change occurred at a different intensity when capsiate continued to be administered after $\mathrm{PH}$. According to FiszerSzafarz and $\mathrm{Nadal}^{16}$, we may consider that the mitotic process was in the $\mathrm{G} 1$ phase as a function of the time elapsed since $\mathrm{PH}(24 \mathrm{~h}$ groups) and also of the action of vincristine, which inhibits the formation of the mitotic spindle and interrupts mitosis at metaphase (all groups). Capsaicin inhibited mitosis as well as the expression of MMP-2, MMP-9 and TIMP-1 in rat hepatic stellate cell cultures and reduced collagen deposition ${ }^{17}$. Thus, capsiate treatment reduced the activity of the lysosome system and the number of mitoses.

The reduction in the number of apoptosis observed after $48 \mathrm{~h}$ in both groups treated with capsiate does not agree with the study by Macho et al. ${ }^{18}$, who showed that capsiate induces apoptosis in tumor cell lines due to an increased production of reactive oxygen species and to the subsequent loss of mitochondrial transmembrane potential. On the other hand, the same review paper previously cited reported that capsaicin can inhibit the autophagic process during the activation of stellate cells ${ }^{17}$. These data suggest that capsiate and capsaicin can act in a similar manner on the process of hepatic hyperplasia.

In the present study, the enzymatic activity of AST was not statistically significant compared to the respective controls. On the other hand, there was a statistically significant increase in ALT and alkaline phosphatase activity for the $\mathrm{CPH} 24$ group, whereas there was no difference in the values obtained after $48 \mathrm{~h}$. Increased ALT activity has been correlated with injury to the hepatocytes ${ }^{19}$.

This increase in alkaline phosphatase in the $\mathrm{CPH}$ group compared to the $\mathrm{PH}$ control (Figure 3) was expected in view of the reduction in the number of mitoses observed after 24 h. This enzyme acts by removing phosphate groups from molecules such as nucleotides and proteins. However, this analysis does not apply to the time of $48 \mathrm{~h}$. The present results lead us to conclude that alkaline phosphatase interfered with the number of mitoses only after the period of $24 \mathrm{~h}$.

Studies involving the administration of capsiate used different doses of this substance and the dose used in the presentstudy was based on what was detected in the pharmaceutical 
market. Bernard et al. ${ }^{20}$ studied the toxicity of capsiate in rats and concluded that the toxic potential of this substance is considered to be very low. Kodama et al. ${ }^{21}$ observed an increase in AST and ALT after administering capsiate to rats for a period of 26 weeks and suggested that this increase occurred due to the fact that the metabolic capacity of the liver was exceeded or hepatocellular damage occurred.

It is known that approximately 14 days after $\mathrm{PH}$ the volume of the remnant liver lobes will be close to the original one, i.e., the volume present before the procedure, with growth ceasing thereafter. Previous capsiate treatment of rats at the dose of $60 \mathrm{mg} / \mathrm{kg} /$ day reduced the number of mitoses $24 \mathrm{~h}$ after $\mathrm{PH}$ and the number of apoptosis $48 \mathrm{~h}$ after $\mathrm{PH}$, and also increased ALT and alkaline phosphatase concentrations at 24 and $24-48 \mathrm{~h}$, respectively. Under the present experimental conditions, capsiate did not show the expected hepatoprotective effect and its administration before surgical hepatic procedures may interfere with the early period of recovery. On this basis, its use is not recommended in such procedures.

\section{Conclusion}

Capsiate treatment preceding hepatic surgery may compromise the initial period of postoperative recovery.

\section{References}

1. Ludy MJ, Moore GE, Mattes RD. The effects of capsaicin and capsiate on energy balance: critical review and meta-analyses of studies in humans. Chem Senses. 2012;37:103-21. doi: 10.1093/chemse/bjr100.

2. Wai K, Yazawa A, Watanabe T. Roles as metabolic regulators of the non-nutrients, capsaicin and capsiate, supplemented to diets. Proc Jpn Acad. 2003;79:207-12. doi: 10.2183/pjab.79B.207.

3. Kobata K, Sutoh K, Todo T, Yazawa S, Iwai
K, Watanabe T. Nordihydrocapsiate, a new capsinoid from the fruits of a nonpungent pepper, Capsicum annuum. J Nat Prod. 1999;62(2):335-6. doi: 10.1021/np9803373.

4. Luo XJ, Peng J, Li YJ. Recent advances in the study on capsaicinoids and capsinoids. Eur J Pharmacol. 2011;650(1):1-7. doi: 10.1016/j. ejphar.2010.09.074.

5. Kobata K, Toda T, Yazawa S, I wai K, Watanabe T. Novel capsaicinoid like substances, capsiate and dihydrocapsiate, from the fruits of a nonpungent cultivar, $\mathrm{CH}-19$ Sweet, of pepper (Capsicum annuum L.). J Agric Food Chem. 1998;46:1695-7. doi: 10.1021/ jf980135c.

6. Ohnuki K, Niwa S, Maeda S, Inoue N, Yazawa S, Fushiki T. CH-19 sweet, a non-pungent cultivar of red pepper, increased body temperature and oxygen consumption in humans. Biosci Biotechnol Biochem. 2001;65(9):2033-6.

7. Macho A, Lucena $C$, Sancho R, Daddario $N$, Minassi A, Muñoz E, Appendino $G$. Non-pungent capsaicinoids from sweet pepper synthesis and evaluation of the chemopreventive and anticancer potential. Eur J Nutr. 2003;42(1):2-9. doi: 10.1007/ s00394-003-0394-6.

8. Lee EJ, Jeon MS, Kim BD, Kim JH, Kwon YG, Lee $\mathrm{H}$, Lee YS, Yang JH, Kim TY. Capsiate inhibits ultraviolet B-induced skin inflammation by inhibiting Src family kinases and epidermal growth factor receptor signaling. Free Radic Biol Med. 2010;48(9):1133-43. doi: 10.1016/j.freeradbiomed.2010.01.034.

9. Pyun BJ, Choi S, Lee Y, Kim TW, Min JK, Kim Y, Kim BD, Kim JH, Kim TY, Kim YM, Kwon YG. Capsiate, a nonpungent capsaicinlike compound, inhibits angiogenesis and vascular permeability via a direct inhibition of Src kinase activity. Cancer Res. 2008;68(1):227-35. doi: 10.1158/00085472.CAN-07-2799.

10. Haramizu S, Kawabata F, Ohnuki K, Inoue $\mathrm{N}$, Watanabe T, Yazawa S, Fushiki T. Capsiate, a non-pungent capsaicin analog, reduces body fat without weight rebound like swimming exercise in mice. Biomed Res. 2011;32(4):279-84. doi: 10.2220/ biomedres.32.279.

11.Kwon DY, Kim YS, Ryu SY, Cha MR, Yon $\mathrm{GH}$, Yang HJ, Kim MJ, Kang S, Park S. Capsiate improves glucose metabolism by 
improving insulin sensitivity better than capsaicin in diabetic rats. J Nutr Biochem. 2013;24(6):1078-85. doi: 10.1016/j. jnutbio.2012.08.006.

12.Li NS, Luo XJ, Dai Z, Liu B, Zhang YS, Yang ZC, Peng J. Beneficial effects of capsiate on ethanol-induced mucosal injury in rats are related to stimulation of calcitonin gene-related peptide release. Planta Med. 2012;78(1):24-30. doi: 10.1055/s-00311280217.

13.Forte GC, Schneider AP. Modulação do gasto energético pela ingestão de capsaicina, cafeína e catequinas: uma revisão sistemática. RBONE. 2012;6(35):207-15.

14.Barros PP, Silva GH, Gonçalves GMS, Oliveira JC, Pagnan LG, Arco-e-Flexa L. Hepatoprotective effect of quercetin pretreatment against paracetamolinduced liver damage and partial hepatectomy in rats. Braz Arch Biol Technol. 2017;60(e16160138): 1-10. doi: 10.1590/1678-4324-2016160138.

15. Higgins GM, Anderson RM. Experimental pathology of the liver. I. Restoration of the liver of the white rat following partial surgical removal. Arch Pathol. 1931;12:186202. doi: 10.2353/ajpath.2010.090675.

16.Fiszer-Szafarz B, Nadal C. Lysosomal enzyme activities in the regenerating rat liver. Cancer Res. 1977;37(2):354-7. PMID: 832261.
17. Bitencourt S, Basso B, Mesquita FC, Oliveira JR. Capsaicin modulates proliferation, migration, and activation of hepatic stellate cells. Cell Biochem Biophys. 2013;1:1-6. doi: 10.1007/s12013-013-9719-0.

18. Macho A, Sancho R, Minassi A, Appendino $G$, Lawen A, Munoz E. Involvement of reactive oxygen species in capsaicinoidinduced apoptosis in transformed cells. Free Radic Res. 2003;37:611-9. doi: 10.1080/1071576031000083215.

19.Pierce AA, Duwaerts CC, Siao K, Mattis AN, Goodsell A, Baron JL, Maher JJ. CD18 deficiency improves liver injury in the MCD model of steatohepatitis. Plos One. 2017;12(9):1-16. doi: 10.1371/journal. pone.0183912.

20. Takanohashi T, Isaka M, Ubukata K, Mihara R, Bernard BK. Studies of the toxicological potential of capsinoids, XIII: inhibitory effects of capsaicin and capsinoids on cytochrome P450 3A4 in human liver microsomes. Int J Toxicol. 2008;27(3):11936. doi: $10.1177 / 1091581809360282$.

21.Kodama T, Watanabe E, Masuyama T, Tsubuku S, Otabe A, Mochizuki M, Bernard BK. Studies of the toxicological potential of capsinoids: II. A 26-week daily gavage dosing toxicity study of $\mathrm{CH}-19$ Sweet extract in rats. Int J Toxicol. 2008;27(Suppl 3):11-27. doi: 10.1080/10915810802513379.

\section{Correspondence:}

Gisele Mara Silva Gonçalves

Faculdade de Ciências Farmacêuticas

Avenida John Boyd Dunlop, s/n

13060-904 Campinas - SP Brasil

Tel.: (55 19)3343-6865

gmsg@puc-campinas.edu.br

Received: Jan 10, 2018

Review: Mar 12, 2018

Accepted: Apr 11, 2018
Conflict of interest: none

Financial source: none
${ }^{1}$ Research performed at Laboratory of Biological Tests, Faculty of Nutrition, Pontifícia Universidade Católica de Campinas (PUCCampinas), Brazil. 